\title{
Compared with insulin glargine, insulin degludec narrows the day-to-day variability in the glucose-lowering effect rather than lowering blood glucose levels*
}

\author{
Susumu Ogawa ${ }^{1,2 \#}$, Kazuhiro Nako1, Masashi Okamura1, Miho Senda ${ }^{1}$, Takuya Sakamoto, \\ Sadayoshi Ito ${ }^{1}$ \\ ${ }^{1}$ Division of Nephrology, Endocrinology and Vascular Medicine, Tohoku University Hospital, Sendai, Japan; \\ ${ }^{\#}$ Corresponding Author: ogawa-s@hosp.tohoku.ac.jp \\ ${ }^{2}$ Center for the Advancement of Higher Education, Tohoku University, Sendai, Japan \\ Received 29 October 2013; revised 19 November 2013; accepted 25 November 2013 \\ Copyright (C) 2013 Susumu Ogawa et al. This is an open access article distributed under the Creative Commons Attribution License, \\ which permits unrestricted use, distribution, and reproduction in any medium, provided the original work is properly cited.
}

\section{ABSTRACT}

Background: Changes in the day-to-day variability in the glucose-lowering effect of insulin [fluctuations of blood glucose levels (BG) seen during the same time period] that occur when insulin glargine (glargine) is replaced with insulin degludec (degludec) have not been sufficiently evaluated. Subjects: Five diabetics with unstable BG undergoing basal-bolus treatment using insulin glargine as basal insulin. Methods: Basal insulin was changed from glargine to same-dose degludec. The subjects' HbA1c, glycoalbumin, and 1.5-anhydro-D-glucitol were measured before and after the switchover. Fasting blood glucose concentration (FBG) and predinner blood glucose concentration (PDBG) were measured continuously for 28 days immediately before the switchover, and 28 days immediately thereafter, to compare and evaluate 1) the changes in their mean values and standard deviations (SDs) before and after the switchover, and 2) the frequency of appearance of $B G$ of over $180 \mathrm{mg} / \mathrm{dL}$ (BG $\geq 180$ ) and under $70 \mathrm{mg} / \mathrm{dL}$ (BG < 70 ), among other items. Bolus insulin remained completely unchanged. Results: The levels of HbA1c, glycoalbumin, FBG's mean value, SDs, $B G \geq 180$ and $B G<70$ all decreased. On the other hand, although PDBG's SD as well as BG $\geq$ 180 and BG < 70 decreased, PDBG's but not FBG's mean values remained unchanged. The levels of 1.5-anhydro-D-glucitol rose. The mean

\footnotetext{
*Disclosure statement: no potential conflicts of interest.
}

values of $B G \geq 180$ decreased in all subjects. Conclusion: The possibility was shown that degludec, to a greater extent than glargine, suppressed daily fluctuations of FBG and PDBG, suppressed the occurrence frequency of hyperglycemia and hypoglycemia, and exerted more steady hypoglycemic actions.

Keywords: Degludec; Glargine; Hyperglycemia; Hypoglycemia; The Day-to-Day Variability in the Glucose-Lowering Effect of Insulin

\section{INTRODUCTION}

Rigorous glycemic control that includes the suppression of glucose spikes is imperative to prevent diabetic complications $[1,2]$. On the other hand, to prolong the life prognosis of patients with diabetes, hypoglycemia must be avoided [3]. In other words, blood glucose levels should ideally be kept within a narrow set range that is not too high or not too low. Insulin basal-bolus treatment (intensive insulin therapy) is being used to attain these conditions. However, there are numerous diabetic patients whose blood glucose levels cannot be sufficiently controlled, even by using this basal-bolus treatment. These patients include those whose blood glucose levels, measured during the same time period, fluctuate dramatically from day to day (Table 1). The fasting blood glucose (FBG) of these patients, for example, may be below $50 \mathrm{mg} / \mathrm{dL}$ in one day, but above $250 \mathrm{mg} / \mathrm{dL}$ on another, making it difficult to set the dose of basal insulin, which is the acting insulin (the insulin that influences blood glucose at a particular time juncture the most 
Table 1. One subject's 4-week record of self-monitored blood glucose (SMBG) for fasting blood glucose (FBG).

\begin{tabular}{cccc}
\hline Day & FBG $(\mathrm{mg} / \mathrm{dL})$ & Day & FBG $(\mathrm{mg} / \mathrm{dL})$ \\
\hline 1 & 217 & 15 & 245 \\
2 & 289 & 16 & 322 \\
3 & 205 & 17 & 178 \\
4 & 197 & 18 & 205 \\
5 & 65 & 19 & 57 \\
6 & 248 & 20 & 285 \\
7 & 350 & 21 & 46 \\
8 & 217 & 22 & 214 \\
9 & 269 & 23 & 309 \\
10 & 304 & 24 & 178 \\
11 & 216 & 25 & 283 \\
12 & 185 & 26 & 37 \\
13 & 62 & 27 & 85 \\
14 & 203 & 28 & 217 \\
\hline
\end{tabular}

strongly). As one reason for this, physicians suggest the difference, with each injection, in the timing of the manifestation of the effects of the basal insulin that is currently being used [4]. In other words, because the way insulin works differs day by day, blood glucose levels, even when measured at the same point in the day, fluctuate dramatically. The recently-developed drug insulin degludec (degludec) is longer-acting than conventional basal insulin, and gives smaller peaks [5]. Moreover, its effects are reported to vary less with each injection [6]. Therefore, in patients it shows dramatic and sharp fluctuations in FBG and pre-dinner blood glucose (PDBG) concentration, despite already undergoing basal-bolus treatment and those whose acting insulin is believed to be basal insulin, their fluctuations in blood glucose are expected to be improved (i.e., stabilized) by replacing their basal insulin with degludec. However, this has not yet been clinically confirmed. We therefore evaluated blood glucose fluctuations in patients manifesting unstable FBG and PDBG despite undergoing basal-bolus treatment using insulin glargine (glargine) as the basal insulin, in case basal insulin had been changed from glargine to same-dose degludec.

\section{METHODS}

The subjects of this study were five patients presenting unstable FBG and PDBG despite undergoing basal-bolus treatment that used glargine as basal insulin.

Table 1 shows one study-subject's 4-week record of self-monitored blood glucose (SMBG) for FBG. Even his/her FBG, which is believed to be least influenced by meals and is stable, varied drastically depending on the day, from a minimum of $37 \mathrm{mg} / \mathrm{dL}$ to a maximum of 350 $\mathrm{mg} / \mathrm{dL}$. In this subject, 8 units of glargine were administered in the morning, and 14 units were administered before going to bed. Therefore, the insulin acting on FBG appears to be glargine taken before going to bed. We raised and lowered the dose in an attempt to make adjustments, but failed. The dose of glargine could be neither increased nor decreased, making blood glucose control extremely difficult. We recruited such patients as study subject.

The definition of unstable blood glucose was determined as follows: "Of the 28 measurements of FBG and PDBG, respectively, hyperglycemia of over $180 \mathrm{mg} / \mathrm{dl}$ [7] occurred more than 10 times, and hypoglycemia of under $70 \mathrm{mg} / \mathrm{dl}[8]$ occurred more than three times; the causes of these blood glucose fluctuations could not be attributed to changes in meals or physical exercise." 180 $\mathrm{mg} / \mathrm{dL}$ is the blood glucose level at which urinary glucose begins to appear. Basal insulin is believed to be the acting insulin for FBG and PDBG; however, pre-lunch blood glucose and pre-bed blood glucose were eliminated from this study, since it would have been necessary to consider the influence on their levels of bolus insulin. We changed the subjects' basal insulin (glargine) to same-dose degludec, and then asked them to carry out self-monitoring of blood glucose levels (FBG and PDBG) every day for the 28 days immediately prior to the change, and the 28 days immediately thereafter. We also evaluated their body mass index (BMI), HbA1c (NGSP), glycoalbumin (GA), and 1.5-anhydro-D-glucitol (1.5-AG) levels immediately before the change and 28 days after the change. The dose of bolus insulin remained unchanged. Japanese regulations stipulate that degludec be administered once daily, so we decided to inject degludec once a day, regardless of the frequency of glargine injections.

The study fully conformed to the Helsinki Declaration and it was approved by the ethics committee of the Tohoku University Hospital. This study was only performed after they had been fully explained to the subjects, and obtaining their informed consent.

\section{STATISTICAL ANALYSIS}

Since all the measurement values evaluated in this study showed a normal distribution (based on ShapiroWilk test), they were shown in the form of mean \pm SD. Paired student's $t$-test was performed to identify any significant differences in the changes in numerical values before and after switching the treatment regimen. $P<$ 0.05 was regarded as significant. 


\section{RESULTS}

We provide basic information of studied subjects as follows, e.g. type (the number of type 1 diabetes subjects $=4$, the number of type 2 diabetes subject $=1$ ), duration of diabetes (15.3 \pm 7.3 years), reasons for basal-bolus treatment (because of 4 type 1 diabetes and a brittle type 2 diabetes), blood pressure (125.3 $\pm 10.2 / 74.2 \pm 5.7$ $\mathrm{mmHg}$ ), blood lipids (triglyceride: $69.7 \pm 30.4 \mathrm{mg} / \mathrm{dL}$, total cholesterol: $186.5 \pm 38.3 \mathrm{mg} / \mathrm{dL}$, high density lipoprotein: $58.9 \pm 5.9 \mathrm{mg} / \mathrm{dL}$ ) and diabetes complications (retinopathy $=3$, neuropathy $=4$ and nephropathy $=2$ ).

Table 2 shows the changes in the subjects' blood glucose control indicators before and after switching basal insulin. Although BMI remained unchanged with the change in treatment, $\mathrm{HbAlc}, \mathrm{GA}$, and 1.5-AG improved significantly. The rate of change was $-5.1 \% \pm 1.3 \%$ for $\mathrm{HbA1c} ;-19.5 \% \pm 4.6 \%$ for $\mathrm{GA}$, and $39.2 \% \pm 8.2 \%$ for 1.5-AG. The dose of basal insulin remained unchanged at $24.4 \pm 5.3 \mathrm{U} /$ day. Glargine was administered twice a day in all subjects but degludec was administered once a day in all subjects. After switching the basal insulin, the mean value of FBG decreased from $212.4 \pm 24.8$ to $179.8 \pm 23.8 \mathrm{mg} / \mathrm{dL}$, and SD decreased from $92.9 \pm 15.2$ to $60.3 \pm 11.8$. In comparison, while the SD of PDBG decreased from $80.7 \pm 7.8$ to $53.8 \pm 4.9$, the mean value decreased from $183.6 \pm 11.0$ to $182.1 \pm 13.5$, which was not a significant change. The maximum value of FBG decreased from $345.4 \pm 33.5 \mathrm{mg} / \mathrm{dL}$ to $292.8 \pm 30.1$ $\mathrm{mg} / \mathrm{dL}$, while the minimum value rose from $40.8 \pm 8.5$ $\mathrm{mg} / \mathrm{dL}$ to $67.8 \pm 18.5 \mathrm{mg} / \mathrm{dL}$. The maximum value of PDBG, moreover, decreased from $336.8 \pm 27.3 \mathrm{mg} / \mathrm{dL}$ to $283.0 \pm 16.6 \mathrm{mg} / \mathrm{dL}$, and the minimum value rose from $49.8 \pm 4.0 \mathrm{mg} / \mathrm{dL}$ to $61.6 \pm 8.9 \mathrm{mg} / \mathrm{dL}$.

Table 3 shows FBG's mean and SD values for each subject before and after changing the treatment regimen, and Table 4 shows the PDBG's mean and SD values for each subject before and after changing the treatment regimen. FBG's mean value decreased in three of the five subjects, but did not show significant changes in two subjects. None of the five subjects showed any significant changes in PDBG's mean value. However, all their $S D$ values had decreased.

Figure 1 shows the changes in mean values and SD values of FBG and PDBG (measured 28 times) in each subject. The mean value of FBG's 28 measurements dropped significantly in 3 of the 5 subjects, but remained unchanged in 2 subjects (Table 3). It had dropped significantly in 5 subjects as a whole (Figure 1(a)). FBG's SD decreased in all 5 subjects, and the mean value also decreased significantly (Figure 1(b)). On the other hand, the mean value of all 28 PDBG measurements remained unchanged in all five subjects (Table 4), and the mean value of the five subjects as a whole did not change (Figure 1(c)). However, SD decreased in all the subjects, and its mean value also decreased (Figure 1(d)). With

Table 2. The changes in the subjects' glycemic control indicators between before and after switching basal insulin.

\begin{tabular}{|c|c|c|c|c|}
\hline Basal insulin & & Glargine & Degludec & $P$ \\
\hline Age & (Years) & \multicolumn{2}{|c|}{$51.2 \pm 16.5(28-72)$} & \\
\hline Gender & (male/female) & \multicolumn{2}{|c|}{$2 / 3$} & \\
\hline Body mass index & $\left(\mathrm{kg} / \mathrm{m}^{2}\right)$ & $22.4 \pm 1.5$ & $22.4 \pm 1.4$ & 0.85 \\
\hline $\mathrm{HbA1c}$ & $(\%)$ & $8.7 \pm 0.4$ & $8.2 \pm 0.4$ & $<0.01$ \\
\hline Glycoalbumin & $(\%)$ & $25.4 \pm 1.2$ & $20.4 \pm 1.1$ & $<0.01$ \\
\hline 1.5-anhydroglucitol & $(\mu \mathrm{g} / \mathrm{mL})$ & $6.7 \pm 0.4$ & $9.2 \pm 0.7$ & $<0.01$ \\
\hline Mean of FBG & $(\mathrm{mg} / \mathrm{dL})$ & $212.4 \pm 24.8$ & $179.8 \pm 23.8$ & $<0.01$ \\
\hline SD of FBG & & $92.9 \pm 15.2$ & $60.3 \pm 11.8$ & $<0.01$ \\
\hline Mean of FBG max & $(\mathrm{mg} / \mathrm{dL})$ & $345.4 \pm 33.5$ & $292.8 \pm 30.1$ & $<0.01$ \\
\hline Mean of FBG min & $(\mathrm{mg} / \mathrm{dL})$ & $40.8 \pm 8.5$ & $67.8 \pm 18.5$ & $<0.01$ \\
\hline Mean of PDBG & $(\mathrm{mg} / \mathrm{dL})$ & $183.6 \pm 11.0$ & $182.1 \pm 13.5$ & 0.79 \\
\hline SD of PDBG & & $80.7 \pm 7.8$ & $53.8 \pm 4.9$ & $<0.01$ \\
\hline Mean of PDBG max & $(\mathrm{mg} / \mathrm{dL})$ & $336.8 \pm 27.3$ & $283.0 \pm 16.6$ & $<0.01$ \\
\hline Mean of PDBG min & $(\mathrm{mg} / \mathrm{dL})$ & $49.8 \pm 4.0$ & $61.6 \pm 8.9$ & $<0.01$ \\
\hline
\end{tabular}

HbA1c: glycated hemoglobin A1c, FBG: fasting blood glucose concentration, PDBG: pre-dinner blood glucose concentration, SD: standard deviation. 
Table 3. FBG's mean and SD values for each subject before and after changing the treatment regimen.

\begin{tabular}{cccccc}
\hline \multirow{2}{*}{ Case } & \multicolumn{3}{c}{ Mean } & \multicolumn{2}{c}{ SD } \\
\cline { 2 - 6 } & Glargine & Degludec & $P$ & Glargine & Degludec \\
\hline 1 & 210.6 & 149.0 & 0.01 & 67.3 & 49.1 \\
2 & 202.8 & 160.3 & 0.02 & 99.8 & 44.6 \\
3 & 218.6 & 208.8 & 0.73 & 107.9 & 76.6 \\
4 & 176.9 & 175.9 & 0.85. & 84.3 & 66.0 \\
5 & 253.4 & 205.3 & 0.04 & 105.1 & 65.3 \\
\hline
\end{tabular}

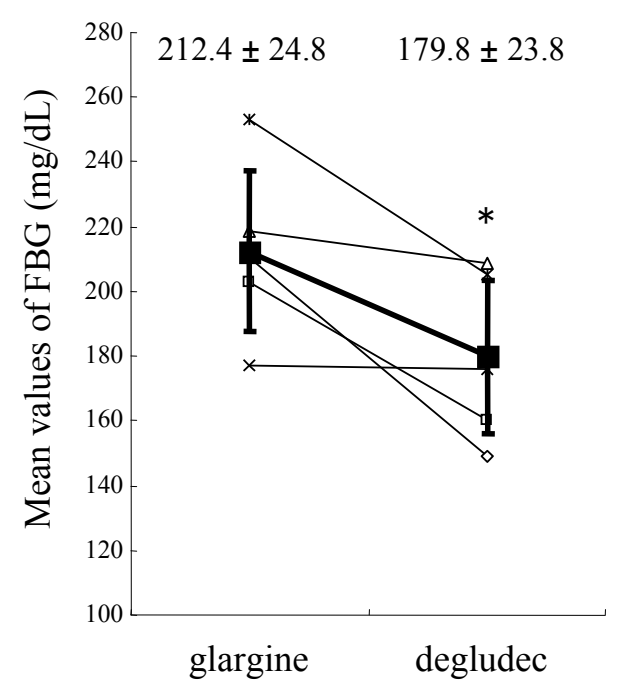

(a)

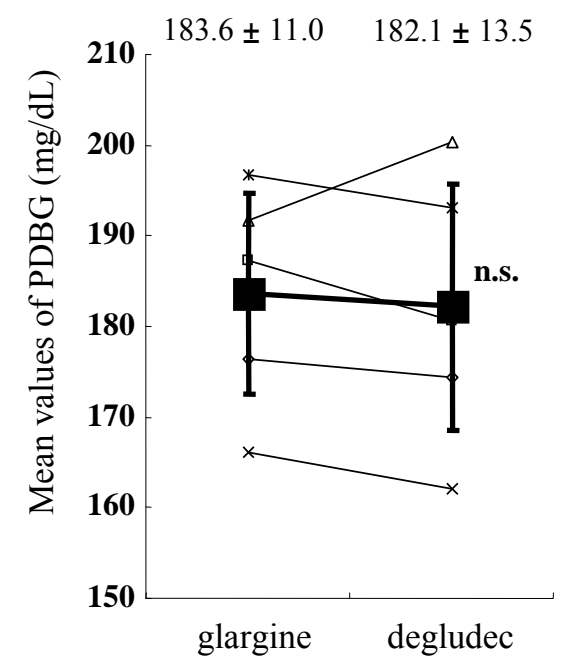

(c)
Table 4. The PDBG's mean and SD values for each subject before and after changing the treatment regimen.

\begin{tabular}{cccccc}
\hline \multirow{2}{*}{ Case } & \multicolumn{3}{c}{ Mean } & \multicolumn{2}{c}{ SD } \\
\cline { 2 - 6 } & G & D & $P$ & G & D \\
\hline 1 & 176.4 & 174.4 & 0.69 & 79.4 & 45.9 \\
2 & 187.2 & 180.5 & 0.66 & 77.5 & 53.2 \\
3 & 191.7 & 200.4 & 0.81 & 96.0 & 61.3 \\
4 & 166.1 & 162.2 & 0.90 & 75.7 & 55.2 \\
5 & 196.8 & 193.0 & 0.87 & 75.1 & 53.4 \\
\hline
\end{tabular}

G: glargine, D: degludec.

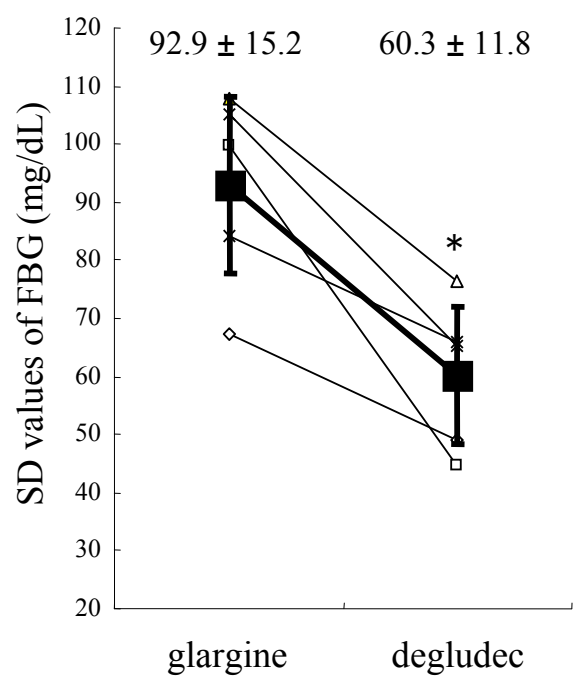

(b)

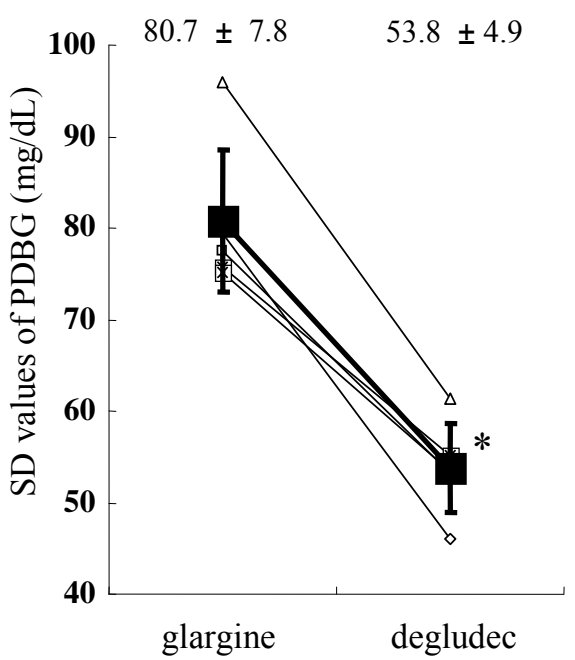

(d)

Figure 1. This figure illustrates the following when basal insulin was changed from glargine to samedose degludec: (1) the changes in each subject's mean values and standard deviations (SD) of fasting blood glucose (FBG) (the changes are shown as thin lines in (a) and (b)); (2) the changes in FBG's mean values and SD's mean values in all five subjects (the changes are shown as bold lines in (a) and (b)); (3) the changes in each subject's mean values and SD of pre-dinner blood glucose (PDBG) (the changes are shown as thin lines in (c) and (d)); and (4) the changes in PDBG's mean values and SD's mean values in all five subjects (the changes are shown as bold lines in (c) and (d)). 
FBG, the mean blood glucose value decreased, and fluctuations (variability in blood glucose levels) were suppressed; while with PDBG, although its mean blood glucose value did not drop, the fluctuations (variability in blood glucose levels) were suppressed. This may be attributable to the fact that, whereas glargine was administered twice a day in all subjects (in the morning and at night), degludec was administered once a day in the evening in all subjects.

Figure 2 shows the changes in frequency of blood glucose levels exceeding $180 \mathrm{mg} / \mathrm{dL}$ or falling below 70 $\mathrm{mg} / \mathrm{dL}$ in FBG ((a), (b)) and PDBG ((c), (d)). By switch-

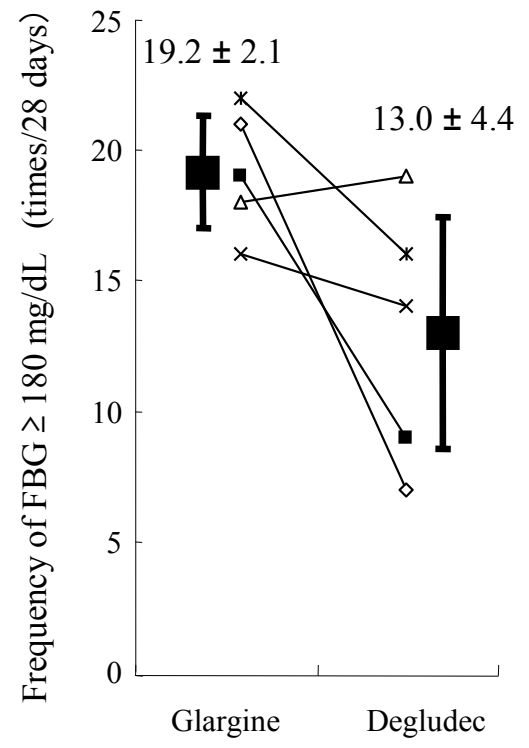

(a)

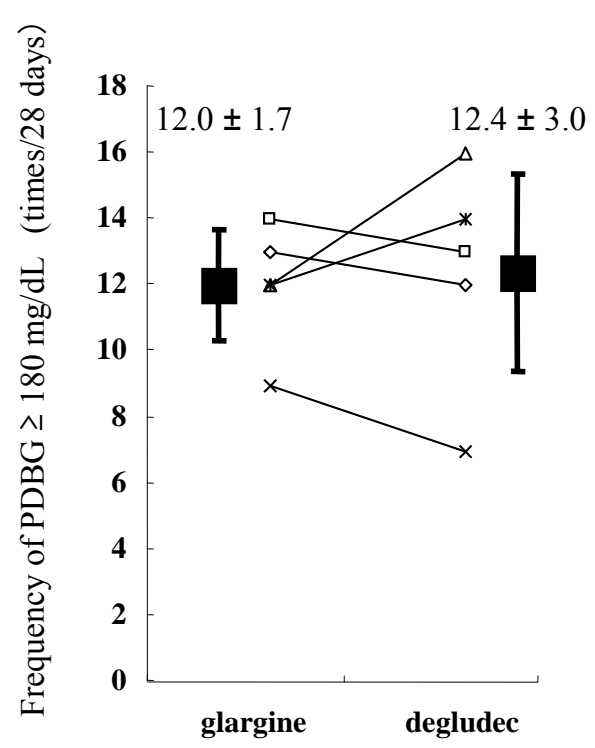

(c) ing from glargine to degludec, the frequency of blood glucose levels exceeding $180 \mathrm{mg} / \mathrm{dL}$ in FBG decreased from $19.2 \pm 2.1$ (times/28 days) to $13.0 \pm 4.4$ (times/28 days), while the frequency of blood glucose levels falling below $70 \mathrm{mg} / \mathrm{dL}$ decreased from $5.0 \pm 1.1$ (times $/ 28$ days) to $0.8 \pm 1.0$ (times/28 days) (Figures 2(a) and (b)). The frequency of FBG exceeding $180 \mathrm{mg} / \mathrm{dL}$ decreased in four subjects and increased in one subject because of the switchover; FBG significantly decreased in five subjects as a whole (Figure 2(a)). Moreover, the frequency of FBG falling below $70 \mathrm{mg} / \mathrm{dL}$ decreased in all five subjects; average FBG also decreased significantly in all

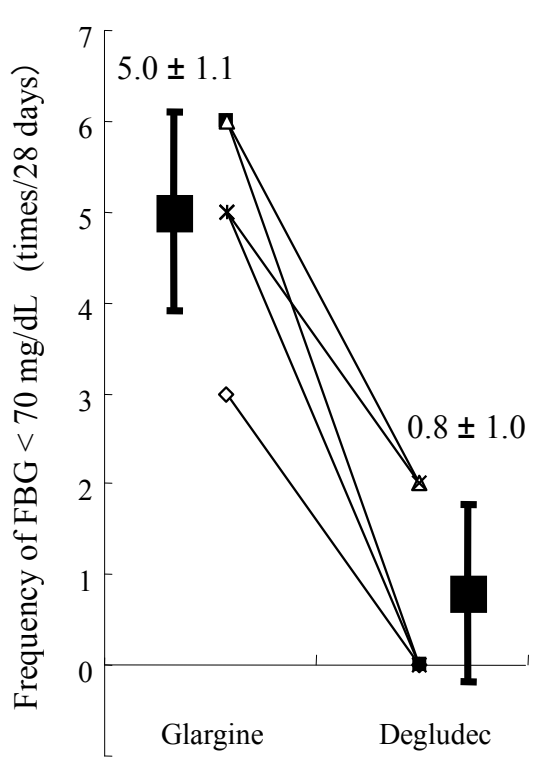

(b)

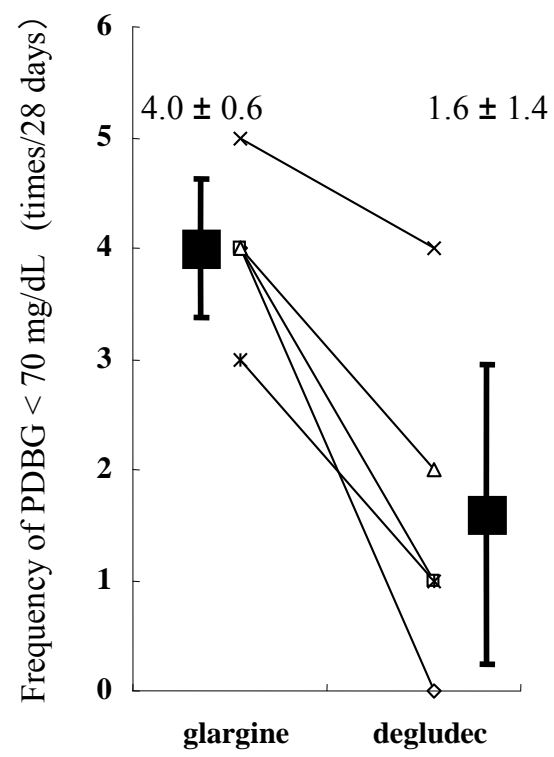

(d)

Figure 2. This figure focuses on each of the 28 measurements of fasting blood glucose (FBG) and pre-dinner blood glucose (PDBG), and shows how the frequency of numerical values exceeding $180 \mathrm{mg} / \mathrm{dL}$ ((a), (c)), and the frequency of the numerical values falling below $70 \mathrm{mg} / \mathrm{dL}((\mathrm{b}),(\mathrm{d}))$ changed if glargine was switched to degludec. 
five subjects as a whole (Figure 2(b)). On the other hand, the frequency of PDBG exceeding $180 \mathrm{mg} / \mathrm{dL}$ decreased in three subjects and increased in two subjects as a result of the switchover. However, no changes in PDBG were seen in five subjects as a whole (Figure 2(c)). In addition, the frequency of PDBG falling below $70 \mathrm{mg} / \mathrm{dL}$ decreased in all five subjects, and PDBG also decreased significantly in these individuals (Figure 2(d)).

Figure 3 plots all the FBG (Figure 3(a)) values and PDBG (Figure 3(b)) values before and after switchover of insulin in each subject. The topmost line shows the frequency of blood glucose levels exceeding $180 \mathrm{mg} / \mathrm{dL}$, and the bottommost line shows the frequency of the blood glucose level falling below $70 \mathrm{mg} / \mathrm{dL}$. The changes in each subject's mean values of FBG and PDBG exceeding $180 \mathrm{mg} / \mathrm{dL}$ are also shown. The frequency of blood glucose levels exceeding $180 \mathrm{mg} / \mathrm{dL}$ in PDBG remained unchanged from $12.7 \pm 1.7$ (times/28days) to $12.4 \pm 3.0$ (times/28days), but the frequency of blood glucose levels falling below $70 \mathrm{mg} / \mathrm{dL}$ decreased from

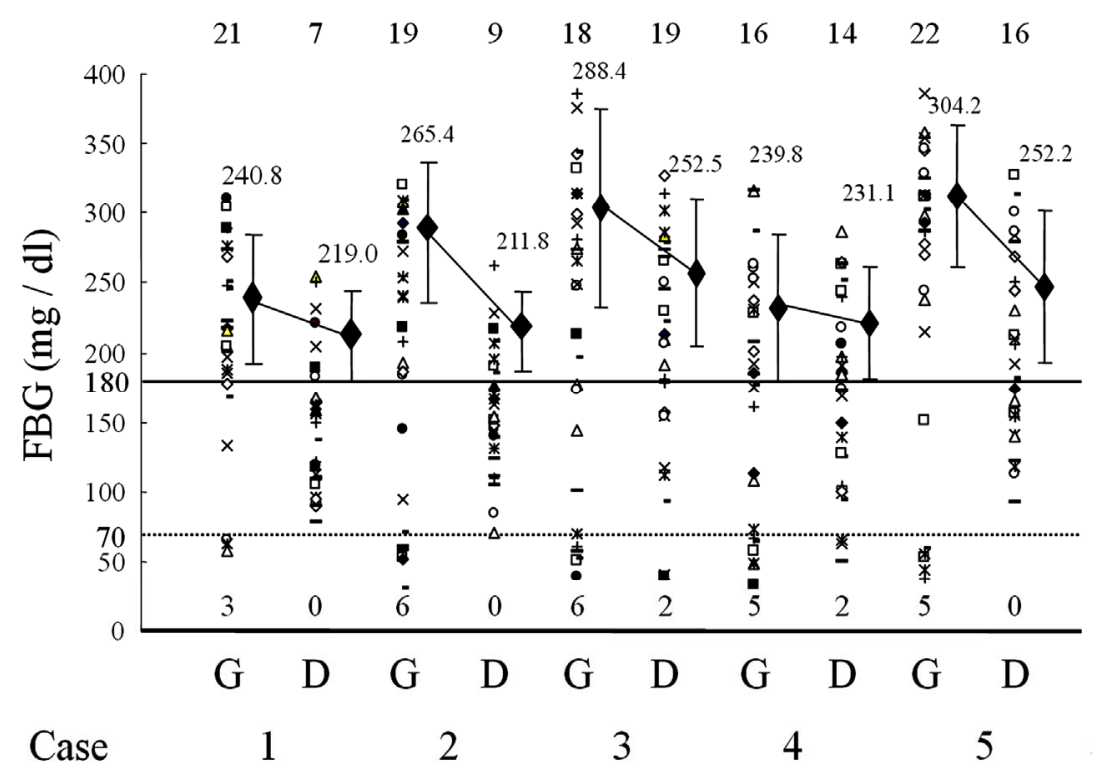

(a)

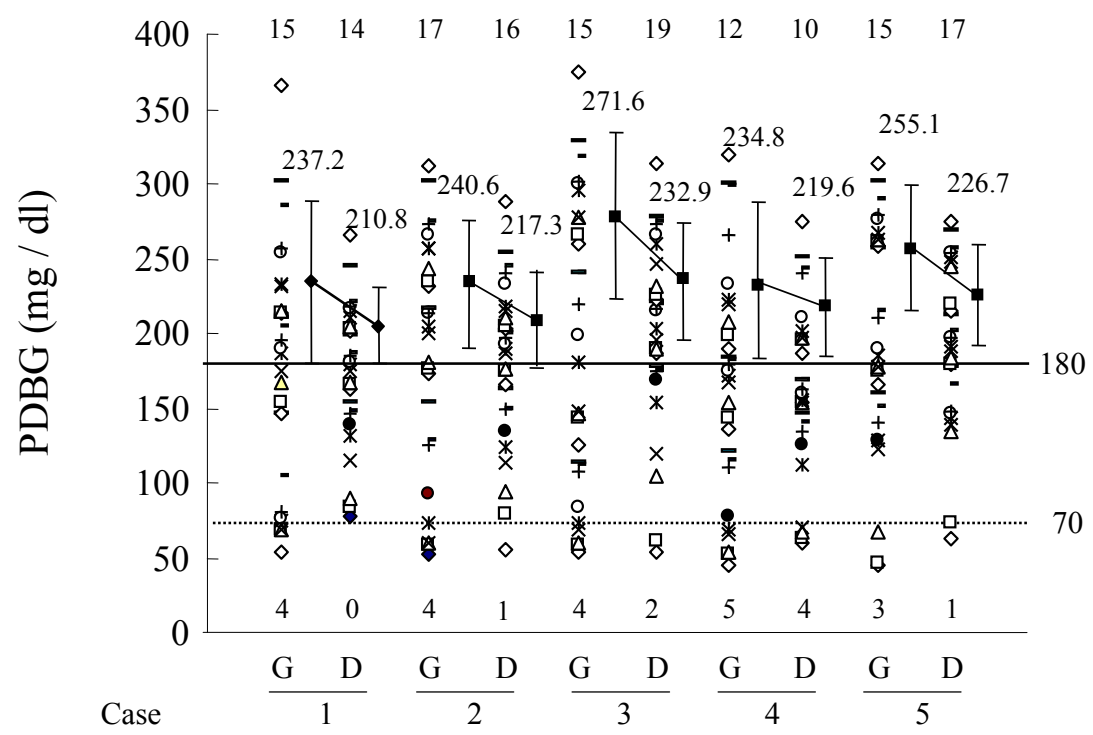

(b)

Figure 3. This figure plots all the fasting blood glucose (FBG) (a) values and pre-dinner blood glucose (PDBG) (b) values before and after switchover of insulin in each subject. The topmost line shows the frequency of blood glucose levels exceeding $180 \mathrm{mg} / \mathrm{dL}$, and the bottommost line shows the frequency of the blood glucose level falling below 70 $\mathrm{mg} / \mathrm{dL}$. The changes in each subject's mean values of DBG and PDBG exceeding 180 $\mathrm{mg} / \mathrm{dL}$ are also shown. 
$4.0 \pm 0.6$ (times/28days) to $1.6 \pm 1.4$ (times/28days). The mean value of blood glucose levels exceeding $180 \mathrm{mg} / \mathrm{dL}$ had decreased in both FBG and PDBG. An examination of the plotting of all the measurement values of FBG and PDBG in these subjects revealed that the fluctuations in blood glucose levels had decreased in all the subjects, and that the blood glucose levels had converged.

Degludec and glargine treatments were well tolerated; no serious adverse events were reported in either treatment. No injection-site reactions or severe hypoglycemic events were reported. In total, 21 confirmed hypoglycemic episodes (self-declaration and/or BG $<70 \mathrm{mg} / \mathrm{dL}$ ) in 5 subjects were observed with degludec compared with 65 episodes with glargine in 5 subjects. Fewer confirmed hypoglycemic episodes were reported for degludec than glargine.

\section{DISCUSSION}

Changing glargine to degludec reduced the mean FBG value but not mean PDBG values. More important, however, is that both the SD values and the fluctuations in blood glucose became smaller (Figure 4). This is because, if blood glucose levels are stabilized, adjustment of the insulin dose is made easier. (If the blood glucose level is always high, you need only to increase the dose of acting insulin; conversely, if it is always low, you need only to decrease its dose.) By switching from glargine to degludec, the mean value of FBG decreased, but that of PDBG remained unchanged. This may have been because, whereas glargine was administered twice a dayin the morning and evening - in all the subjects (with the exception of one), degludec was administered once a day in the evening. Glargine has a shorter duration of action than degludec; however, if administered in the morning as well, its effectiveness in reducing pre-dinner blood glucose appears to be not inferior to that of degludec. Since fluctuations were seen in the effects, however, hyperglycemic $(\geq 180 \mathrm{mg} / \mathrm{dL})$ days and hypoglycemic $(<70$ $\mathrm{mg} / \mathrm{dL}$ ) days were believed to have occurred frequently, increasing the SD. Due to this switchover from glargine to degludec, the SD values of both FBG and PDBG decreased, so degludec appears to have exerted more steady hypoglycemic actions (the day-to-day variability in the glucose-lowering effect is narrow) on a fasting and prior to dinner. In other words, the appearance of insulin action from about 8 hours after injection to about 15 hours was believed to change less for each injection of degludec than with glargine $[4,6]$.

Because of the switchover to degludec, all the indicators of blood glucose control, namely HbAlc, GA, and 1.5-AG, improved. The rate of improvement was the greatest in $1.5-\mathrm{AG}$, followed by $\mathrm{GA}$ and $\mathrm{HbAl} \mathrm{c}$, in that order. The major reason for this may have been that the evaluation period was short, at only 28 days. The sup-

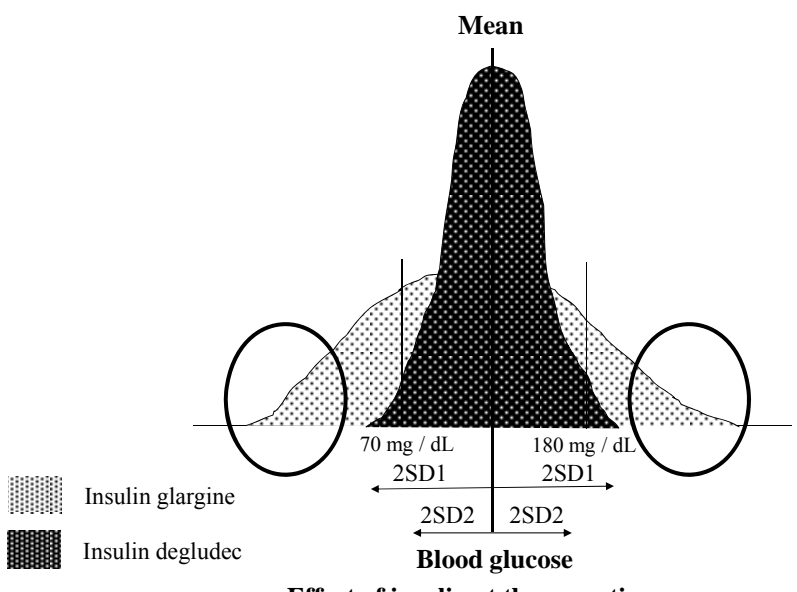

Effect of insulin at the same time

Figure 4. This figure schematically shows the changes in blood glucose distribution that occurred as a result of switching from insulin glargine to insulin degludec. Even though the mean blood glucose value did not change very sharply, the SD narrowed (from SD1 to SD2), so the frequency of hyperglycemia exceeding $180 \mathrm{mg} / \mathrm{dL}$ and hypoglycemia falling below 70 $\mathrm{mg} / \mathrm{dL}$ appears to have decreased. Especially problematic is the reduction in the number of events of severe hypoglycemia of below $50 \mathrm{mg} / \mathrm{dL}$ and severe hyperglycemia of over $200 \mathrm{mg} / \mathrm{dL}$ (inside the circle in the diagram). This is because the blood glucose levels at both of these extremes are the most strongly related to the onset of such events in the patients. In other words, this shows that manifestation of insulin effects at the same time period is markedly more constant in degludec than in glargine.

pression of a rise in blood glucose levels during brief periods that are unlikely to be reflected in HbAlc (but which are reflected in GA values), as well as a reduction in the frequency and numerical value of blood glucose levels exceeding the level at which urinary glucose generally begins appearing $(\geq 180 \mathrm{mg} / \mathrm{dL})$ (reflected in 1.5AG values), were largely reflected in GA and 1.5-AG values, to a greater extent than HbAlc values. In other words, minor fluctuations in blood glucose appear to have decreased. This also shows that degludec demonstrated more steady hypoglycemic actions (the day-today variability in the glucose-lowering effect is narrow) than glargine.

One option for patients with wide blood glucose fluctuations that make setting the dose of long-acting insulin difficult may be to switch long-acting insulin to degludec with the aim of stabilizing their blood glucose level.

\section{CONCLUSION AND LIMITATION}

The biggest problem with this study is the very small sample size and a single arm non-controlled study. Thus, it will be necessary to carry out further studies on a larger scale randomized control trial or cross-over study. The number of the study participants was too small to draw any firm conclusion. Because this was a single arm 
non-controlled study, the improved glycemic fluctuation could be explained by "regression to the mean" phenomenon. The sample size was too small to do the analysis and to compare the efficacy and safety of insulin degludec and insulin glargine in diabetic patients. However, this report is a previous work to lead a further research in the future. We hope our report becomes provisions of a further research in the future.

\section{ACKNOWLEDGEMENTS}

The authors acknowledge the editorial assistance and clinical support of Miss Manami Simizu for her help with preparing the references and for their expert assistance with the management of clinical data. We would like to express our sincere gratitude to all the study subjects who measured with many SMBG for this study.

\section{REFERENCES}

[1] Holman, R.R., Paul, S.K., Bethel, M.A., Matthews, D.R. and Neil, H.A. (2008) 10-year follow-up of intensive glucose control in type 2 diabetes. New England Journal of Medicine, 359, 1577-1589. http://dx.doi.org/10.1056/NEJMoa0806470

[2] Nathan, D.M., Cleary, P.A., Backlund, J.Y., Genuth, S.M., Lachin, J.M., Orchard, T.J., Raskin, P., Zinman, B., Diabetes Control and Complications Trial/Epidemiology of Diabetes Interventions and Complications (DCCT/EDIC) Study Research Group (2005) Intensive diabetes treatment and cardiovascular disease in patients with type 1 diabetes. New England Journal of Medicine, 353, 26432653. http://dx.doi.org/10.1056/NEJMoa052187

[3] NICE-SUGAR Study Investigators, Finfer, S., Liu, B., Chittock, D.R., Norton, R., Myburgh, J.A., McArthur, C., Mitchell, I., Foster, D., Dhingra, V., Henderson, W.R., Ronco, J.J., Bellomo, R., Cook, D., McDonald, E., Dodek,
P., Hébert, P.C., Heyland, D.K. and Robinson, B.G. (2012) Hypoglycemia and risk of death in critically ill patients. New England Journal of Medicine, 367, 1108-1118. http://dx.doi.org/10.1056/NEJMoa1204942

[4] Heise, T., Nosek, L., Rønn, B.B., Endahl, L., Heinemann, L., Kapitza, C. and Draeger, E. (2004) Lower within-subject variability of insulin detemir in comparison to NPH insulin and insulin glargine in people with type 1 diabetes. Diabetes, 53, 1614-1620. http://dx.doi.org/10.2337/diabetes.53.6.1614

[5] Heise, T., Nosek, L., Bøttcher, S.G., Hastrup, H. and Haahr, H. (2012) Ultra-long-acting insulin degludec has a flat and stable glucose-lowering effect in type 2 diabetes. Diabetes, Obesity and Metabolism, 14, 944-950. http://dx.doi.org/10.1111/j.1463-1326.2012.01638.x

[6] Heise, T., Hermanski, L., Nosek, L., Feldman, A., Rasmussen, S. and Haahr, H. (2012) Insulin degludec: Four times lower pharmacodynamic variability than insulin glargine under steady-state conditions in type 1 diabetes. Diabetes, Obesity and Metabolism, 14, 859-864. http://dx.doi.org/10.1111/j.1463-1326.2012.01627.x

[7] Moghissi, E.S., Korytkowski, M.T., DiNardo, M., Einhorn, D., Hellman, R., Hirsch, I.B., Inzucchi, S.E., Ismail-Beigi, F., Kirkman, M.S. and Umpierrez, G.E. American Association of Clinical Endocrinologists; American Diabetes Association (2009) American Association of Clinical Endocrinologists and American Diabetes Association consensus statement on inpatient glycemic control. Diabetes Care, 32, 1119-1131. http://dx.doi.org/10.2337/dc09-9029

[8] Seaquist, E.R., Anderson, J., Childs, B., Cryer, P., Dagogo-Jack, S., Fish, L., Heller, S.R., Rodriguez, H., Rosenzweig, J. and Vigersky, R. (2013) Hypoglycemia and diabetes: A report of a workgroup of the American Diabetes Association and the Endocrine Society. Diabetes Care, 36, 1384-1395. http://dx.doi.org/10.2337/dc12-2480 